\title{
Book Lovers, Technophiles, Pragmatists, and Printers: The Social and Demographic Structure of User Attitudes toward e-Books
}

\section{Andy Revelle, Kevin Messner, Aaron Shrimplin, and Susan Hurst}

This article is based on Kevin Messner, Andy Revelle, Aaron Shrimplin, and Susan Hurst, "Book Lovers, Technophiles, Printers, and Pragmatists: The Social and Demographic Structure of User Attitudes Toward e-Books," Proceedings of the 15th Annual Conference Association of College E Research Libraries (ACRL), Philadelphia, Pa., April 2011.

\begin{abstract}
Q-methodology was used to identify clusters of opinions about e-books at Miami University. The research identified four distinct opinion types among those investigated: Book Lovers, Technophiles, Pragmatists, and Printers. The initial Q-methodology study results were then used as a basis for a large-n survey of undergraduates, graduate students, and faculty so that we could have a more complete picture of the demographic and social makeup of the campus population. Results from that survey indicate that academic discipline is strongly associated with the respondents' opinion types. Gender and educational status are also associated with respondents' opinion types.
\end{abstract}

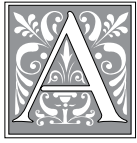

s academic libraries ramp up their investments in e-book collections and experiment with a growing range of purchasing models, they need to know more about how their users view e-books and what expectations users bring to library collections. In 2007-2008, our research team conducted a study using Q-methodology to identify opinions about e-books among the population of library users at Miami University in Oxford, Ohio. ${ }^{1}$ Q-methodology is a well-established research method used to study people's subjectivity (or, put differently: how people think about a topic). ${ }^{2}$ Typically, a Q-study involves a few basic steps. After opinion statements are collected about a topic of interest, subjects are asked to rank them on a positive-to-negative scale, a process

Andy Revelle is Social Sciences Librarian, Kevin Messner is Life Sciences Librarian, Aaron Shrimplin is Assistant Dean for Reference and Collection Services, and Susan Hurst is Business Librarian at Miami University; e-mail: revellaa@muohio.edu,messnekr@muohio.edu,shrimpak@muohio.edu, hurstsj@muohio.edu. (C) 2012 Andy Revelle, Kevin Messner, Aaron Shrimplin, and Susan Hurst, Attribution-NonCommercial (http://creativecommons.org/licenses/by-nc/3.0/) CC BY-NC 
known as a Q-sort. It is in the ranking of the statements that a person's subjectivity is revealed. Finally, completed Q-sorts are analyzed using a statistical technique called factor analysis. Each factor that emerges from the analyzed Q-sorts indicates shared viewpoints or segments of subjectivity. The e-book research identified four distinct opinion types among those surveyed, which we labeled Book Lovers, Technophiles, Pragmatists, and Printers.

Book Lovers have an inherent affinity for the print form. They cherish books as physical objects. Leisure reading is a very important component of their opinion on e-books, and they cannot imagine reading an e-book for pleasure. Finally, they strongly dislike reading longer texts off a screen and feel as if they don't absorb information as well when they do.

Technophiles are strongly interested in the possibilities of new technology as regards the book. They feel as if the advantages in searching and access outweigh any downsides to e-books. The idea of being able to conduct research without making a trip to the library excites them and they have no trouble reading text from a screen.

Pragmatists are the most neutral of the four types isolated, as they are most interested in content and see pros and cons to both formats. They like the searchability of e-books and feel that this feature allows them to filter out unwanted content. On the downside, they feel that the loss of the ability to make margin notes interrupts their workflow. They would not like to read an entire book on the computer screen, but this feeling plays a lower role in their assessment of the medium because they rarely consume entire books.

Printers prefer print books but are distinguished from Book Lovers in that they have specific difficulties with the usability of e-books. This group simply cannot read text on a screen and needs to print any online texts with which they work. ${ }^{3}$

Q-methodology lets us say with confidence that these four distinct viewpoints exist on campus. As a research method, however, it is designed to expose opinion types but not what proportion of the campus falls into each viewpoint and their respective demographic makeup. In other words, we didn't know what percentage of faculty was Book Lovers compared to Pragmatists, nor did we know whether or not more women than men were Technophiles. Issues of gender, departmental affiliation, and university status were of particular interest. To answer these and other related questions about the social and demographic structure of user attitudes toward e-books, we conducted a follow-up, large-n survey of the Miami University population in spring 2009. This paper presents the results of that research.

\section{Literature Review}

Several studies of e-book users' attitudes and perceptions within higher education have been reported in recent years, with mixed findings. Recently, OnCampus Research surveyed U.S. college students on their use and preferences for e-textbooks, finding a strong overall preference for print books and limited uptake of ebooks. ${ }^{4}$ The Joint Information Systems Committee (JISC) conducted one of the largest-scale studies of e-book use and users to date, with over 20,000 subjects at 120 U.K. institutions. Their results indicated broad, growing use of e-books and general acceptance of the format. ${ }^{5}$ Primary Research Group surveyed student views of e-books from approximately 250 U.S. higher education institutions, noting strong links between use of the format and socioeconomic status. ${ }^{6}$ Ebrary's 2007 and 2008 surveys of faculty and students worldwide, which included attitudinal questions, revealed overall poor awareness and skepticism toward the format. ${ }^{7}$ A number of smaller studies using survey or focus group methods at individual institutions have also been undertaken, again with varying results but often revealing considerable user skepticism about e-books. $^{8}$ 


\section{Methods}

During a presentation of the initial findings at ACRL 2009, many of the attendees' questions focused on issues that our Q-methodology research was unable to answer: namely, what percentage of the campus population fell into each of the four opinion types and the unifying characteristics of each of those viewpoints. ${ }^{9}$ To address these questions, the initial Q-methodology study results were used as a basis for a large-n online survey. The survey instrument was constructed using the opinion statements taken from the original Q-methodology study. As in that study, the term e-book was intentionally left undefined to allow respondents to reply using their own conceptions of the medium. Statements were chosen that most strongly defined each opinion type (see table 1). Survey participants responded to each of the statements using a 5-point, "strongly agree/ strongly disagree" Likert scale. We also included an open-ended question to elicit qualitative data. This question asked, "If the library decided to start primarily purchasing electronic books rather than print, how would you feel about this decision and why?" This question was designed to be deliberatively provocative to elicit definitive responses for use in mapping respondents to the four opinion types. To ascertain the demographic makeup of each opinion type, we asked the respondent's age, gender, and departmental affiliation. We also queried respondents concerning their past exposure to e-books, positing that increased exposure might have an impact on their opinion of the medium. Finally, we asked questions about technology and Internet usage, including which technologies respondents used and the amounts of time they spent using them.

We distributed invitations to participate in the survey via a mass e-mailing to the campus community. All faculty, staff, and graduate students received invitations, as well as a random sampling of the undergraduate population. In total, 15,241 invitations were sent and 1,471 people participated in the survey, yielding a response rate of 9.65 percent. The survey was conducted using Miami University's Prezza Checkbox license. As such, all responses were stored on secure university servers. Each respondent was offered the chance to enter a drawing for one of ten $\$ 100$ gift cards as an incentive to complete the survey. To ensure confidentiality, the contact information necessary to award the gift cards was collected using a separate database, eliminating any link of personal information to the corresponding survey responses.

\section{Data Analysis}

Survey data were analyzed using SPSS. As a first step, the ten respondents who identified themselves as never having used an electronic book were excluded from further analysis. Next we looked at the open-ended question. Approximately 16 percent left this question blank, and those respondents were also removed from the analysis. Those who did respond to the open-ended question ("If the library decided to start primarily purchasing electronic books rather than print, how would you feel about this decision and why?") had their responses scored to one of the four opinion types (Book Lovers, Technophiles, Pragmatists, and Printers). While the scoring was necessarily subjective, due to the nature of the responses, all scoring was done by one researcher to foster consistency, and both content and context of the responses were considered. The open-ended question was separated from the other responses prior to scoring, so the scorer had no knowledge of the other responses. In cases where the scorer was uncertain, the entire team attempted to form a classification consensus. At the end, there were 90 open-ended question responses that were deemed unclassifiable by the team; those were also dropped from further analysis, leaving 1,135 respondents. The results of the open-ended response categorizations were as follows: 31 percent Book Lovers, 22 percent Technophiles, 19 percent Pragmatists, and 28 percent Printers. 
Many of the responses to the openended question mirrored those found by previous researchers, particularly the U.K. research by the Joint Information Systems Committee. ${ }^{10}$ The similarities included a continued preference by many academic users in both the United States and the United Kingdom for access to both print and online versions, as well as similar statements both pro and con concerning e-book access and usage. To further examine the open-ended re-

\begin{tabular}{|c|c|c|}
\hline \multicolumn{3}{|c|}{$\begin{array}{c}\text { TABLE } 1 \\
\text { Survey Questions Used to Classify Respondents by Opinion Type }\end{array}$} \\
\hline Number & Question Text & $\begin{array}{l}\text { Used in Formula for } \\
\text { Opinion(s) }\end{array}$ \\
\hline Q1 & $\begin{array}{l}\text { There is just something about sitting down } \\
\text { and actually reading a physical book. }\end{array}$ & Book Lover $(+)$ \\
\hline Q2 & $\begin{array}{l}\text { I personally think having e-books would de- } \\
\text { feat the purpose of having a physical library. }\end{array}$ & Technophile (-) \\
\hline Q3 & I do not really see a downside to e-books. & Book Lover (-) \\
\hline Q4 & $\begin{array}{l}\text { I love that about e-text, that I can do text } \\
\text { search. }\end{array}$ & Technophile $(+)$, Pragmatist $(+)$ \\
\hline Q5 & $\begin{array}{l}\text { There are times when it is beneficial to have } \\
\text { a paper book, so that I can write on it, or } \\
\text { view it anywhere. }\end{array}$ & Pragmatist $(+)$ \\
\hline Q6 & $\begin{array}{l}\text { It is hard when there is only one copy of a } \\
\text { print book and someone else has it; if every- } \\
\text { thing was online then that would not be a } \\
\text { problem and everyone could have access to it. }\end{array}$ & Technophile $(+)$ \\
\hline Q7 & $\begin{array}{l}\text { I do not like to just read stuff online; I have } \\
\text { to print it. So e-books would be good if you } \\
\text { could print the stuff out that you needed. }\end{array}$ & Printer $(+)$ \\
\hline Q8 & $\begin{array}{l}\text { Electronically, I can go back and forth a lot } \\
\text { faster. My intellectual process flows more } \\
\text { smoothly with the electronic copy. }\end{array}$ & Printer $(-)$ \\
\hline Q9 & $\begin{array}{l}\text { Reading off a monitor is just as easy as read- } \\
\text { ing off paper; it would be great for me. }\end{array}$ & Book Lover (-), Printer (-) \\
\hline Q10 & $\begin{array}{l}\text { There are certain books that I have passed } \\
\text { by, because there was not an electronic } \\
\text { resource of it, because I did not want to tote } \\
\text { another thing in my bag. }\end{array}$ & Pragmatist (-) \\
\hline Q11 & $\begin{array}{l}\text { I find that when I am reading material on } \\
\text { a computer, I absorb it less. I print it so I } \\
\text { can absorb more info and refer to multiple } \\
\text { articles at the same time. }\end{array}$ & Printer $(+)$ \\
\hline Q12 & I am not comfortable reading e-books online. & Technophile (-), Pragmatist (-) \\
\hline Q13 & $\begin{array}{l}\text { When it comes to my leisure reading, I will } \\
\text { probably want to have the actual book. }\end{array}$ & Book Lover $(+)$ \\
\hline \multicolumn{3}{|c|}{ - respondent must disagree or be neutral with statement to qualify as opinion type } \\
\hline & must agree or be neutral with statement t & alify as opinion type \\
\hline
\end{tabular}


sponses, we analyzed the complete body of words used in response to the openended question using a Visual Basic for Applications script in MS Excel. Unique words and their frequency were calculated. We removed common "stop" words and conducted a stemming procedure to combine words with the same root and sense. We used the resulting list of words and frequencies to generate a word cloud using the Web-based tool Wordle (http:// www.wordle.com/) (see figure 1). A total of 1,800 unique words were encountered; unsurprisingly, the word "books" was most frequent, with 1,593 instances. As one point of interest, we noted the high frequency of the words "both" (159 uses, 20th highest incidence) and "also" (104 uses, 41st highest incidence) in the word cloud. We speculated that these word frequencies might indicate a common user desire for availability of print and e- formats together; a review of the incidences of these terms in the original responses showed this was the case in 70 percent of responses using "both" or "also."

Once the open-ended responses were coded, four formulae were created using the questions from the survey (see table
1). Respondents were coded as Book Lovers if they answered Questions \#1 and \#13 as No Opinion, Agree, or Strongly Agree and they answered Questions \#3 and \#9 as Strongly Disagree, Disagree, or No Opinion. (Respondents also had to be coded as Book Lovers on the open-ended question.) Respondents were coded as Technophiles if they answered Questions \#4 and \#6 as No Opinion, Agree, or Strongly Agree and they answered Questions \#2 and \#12 as Strongly Disagree, Disagree, or No Opinion. (Respondents also had to be coded as Technophiles on the open-ended question.) Respondents were coded as Pragmatists if they answered Questions \#4 and \#5 as No Opinion, Agree, or Strongly Agree and they answered Questions \#10 and \#12 as Strongly Disagree, Disagree, or No Opinion. (Respondents also had to be coded as Pragmatists on the open-ended question.) Respondents were coded as Printers if they answered Questions \#7 and \#11 as No Opinion, Agree, or Strongly Agree and they answered Questions \#8 and \#9 as Strongly Disagree, Disagree, or No Opinion. (Respondents also had to be coded as Printers on the open-ended question.) Of the

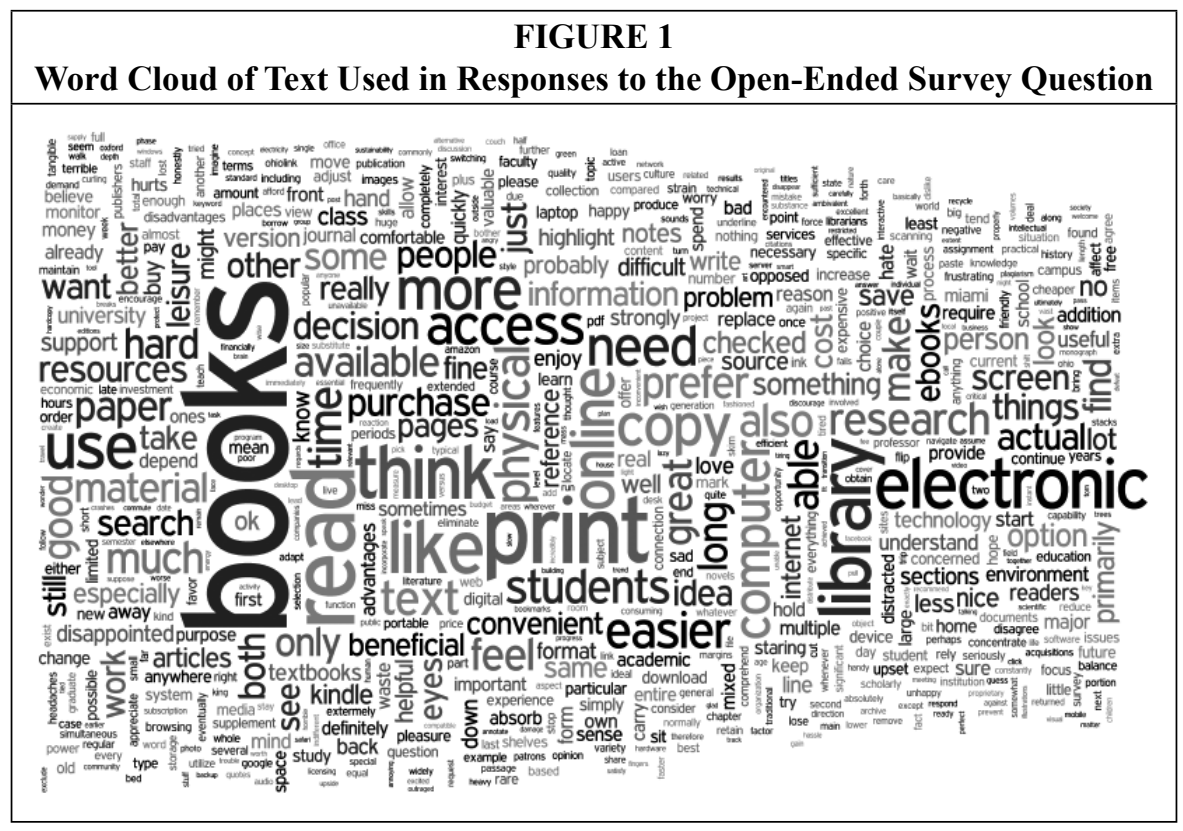




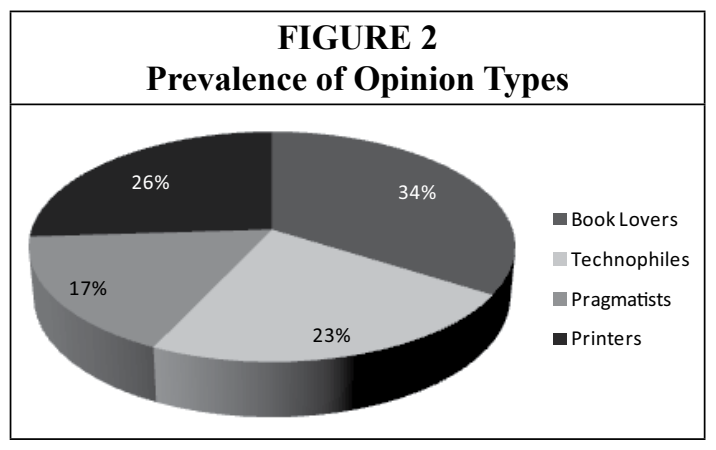

distributions $(p=0.000)$. One explanation might be that men are more defined by the media type (37\% preferring print books, $27 \%$ identifying as technophiles), whereas women appear to be more focused on print but are evenly split between preferring original print books versus those comfortable printing out electronic versions. Looking at it another way, only 35 percent

1,135 respondents in our data set, 1,025 were included in the coding process. (A total of 110 respondents failed to answer one or more of the questions used in the four formulae and consequently could not be included in the analysis.) Of those 1,025 responses, $735(71 \%)$ met all the conditions of one of these four formulae and thus fit into one of the four opinion types. The remainder may represent one or more additional viewpoints not yet characterized, or respondents with less strongly held viewpoints, or spurious responses, or a mixture.

\section{Demographic Analysis}

Overall, our initial analysis of the 735 fully characterized respondents indicated that Book Lovers make up 34 percent (249), Technophiles 23 percent (168), Pragmatists 17 percent (126), and Printers 26 percent (192) of the identified sample (see figure 2). Examination of the prevalence of these four identified opinion types within various demographic groups showed several correlations.

Looking at gender, 32 percent of women identified as Book Lovers and another 32 percent of women identified as Printers (see figure 3). This compares to 37 percent of men identifying as Book Lovers, but just 16 percent identifying with the Printer opinion type. Pearson's chi-square test of independence indicated a statistically significant difference between the two gender of women (20\% Technophiles, $15 \%$ Pragmatists) indicated they were comfortable reading online, compared to a total of 47 percent of the male population (27\% Technophiles, 20\% Pragmatists). This finding supports Rowlands et al's conclusion that, among e-book users, men are more likely to read from a screen than women. ${ }^{11}$ Considering the skewed gender ratios at some institutions or in specific departments, this finding could have real significance for collection development.

This leads us to our next area of interest: university departmental affiliations. Here we see striking differences among the subgroups as well. In the Natural Sciences,

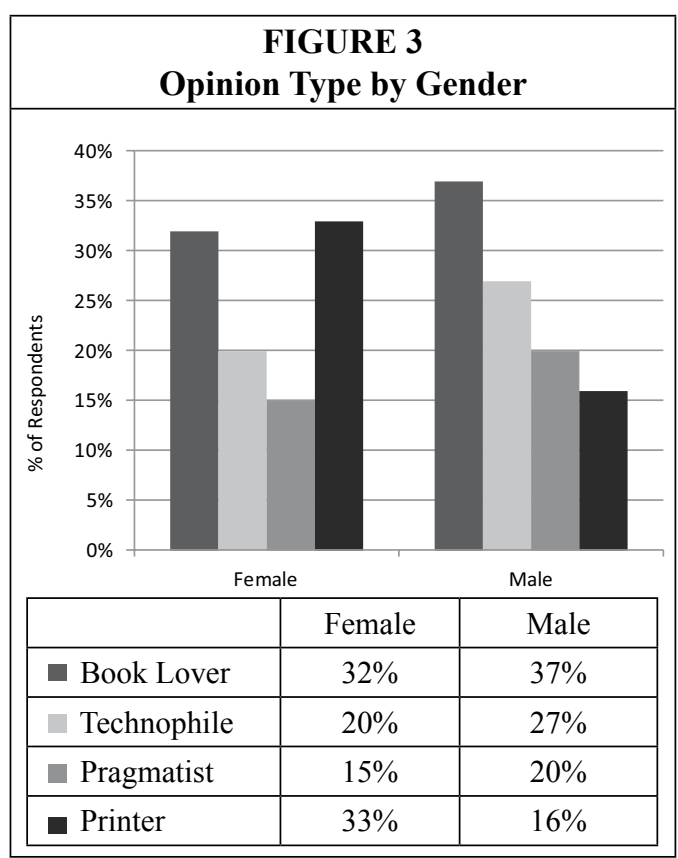


the four opinion types are nearly equally distributed (see figure 4). In the Social Sciences, Book Lovers and Printers are the most prevalent, a pattern seen even more strongly in Education. In the Humanities, as we might suspect, there is a substantial skew, with half of the respondents identifying as Book Lovers and smaller numbers in the other three opinion categories; with a similar pattern (although not as strong) for those in Fine Arts. Not surprisingly though, in the fields of Business and Engineering, Technophiles were the largest group. However, in Engineering, all four categories were evenly distributed, whereas in Business there was a fairly even distribution between Technophiles, Printers, and Book Lovers, but only a very small population of Pragmatists (7\%). Nonacademic department staff were primarily Book Lovers, with the rest of their numbers being evenly distributed across the remaining three opinion types. A chi-square test of independence confirmed that the differences between these distributions were statistically significant $(p=0.000)$. Hence it appears that distinct differences do exist between academic disciplines, with Humanities, Education, and Fine Arts in particular preferring print books while those in Engineering and Business appearing more interested in online materials.

We acknowledge that, given the differences in gender described above, in some cases apparent preferences within a discipline may be attributable to gender prevalence within that discipline. For example, within the humanities, significant differences exist between men's and women's opinion types (see figure 5). Since 68 percent of the humanities' respondents were women, the discipline reflects women's opinions more strongly. However, when examined separately, the opinions of women and men in the humanities remained statistically significantly different from those of women and men overall ( $p$ $=0.004$ and 0.03 , respectively), suggesting that, irrespective of gender, disciplinary status is a component of their attitudes.

In engineering, another case with a substantial gender predominance, no difference is apparent between the opinion types of men and women $(p>0.999$ in Fisher's exact test, used due to small sample size). Hence, gender prevalence does not appear to play a role in this

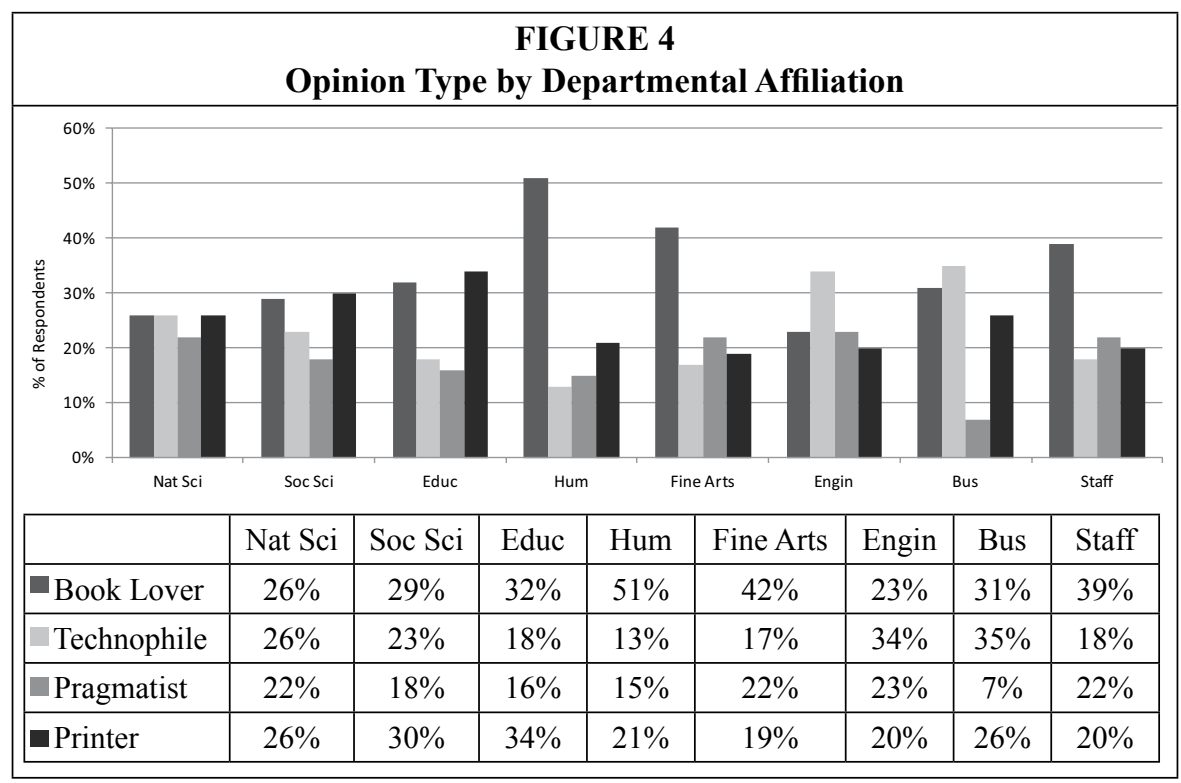




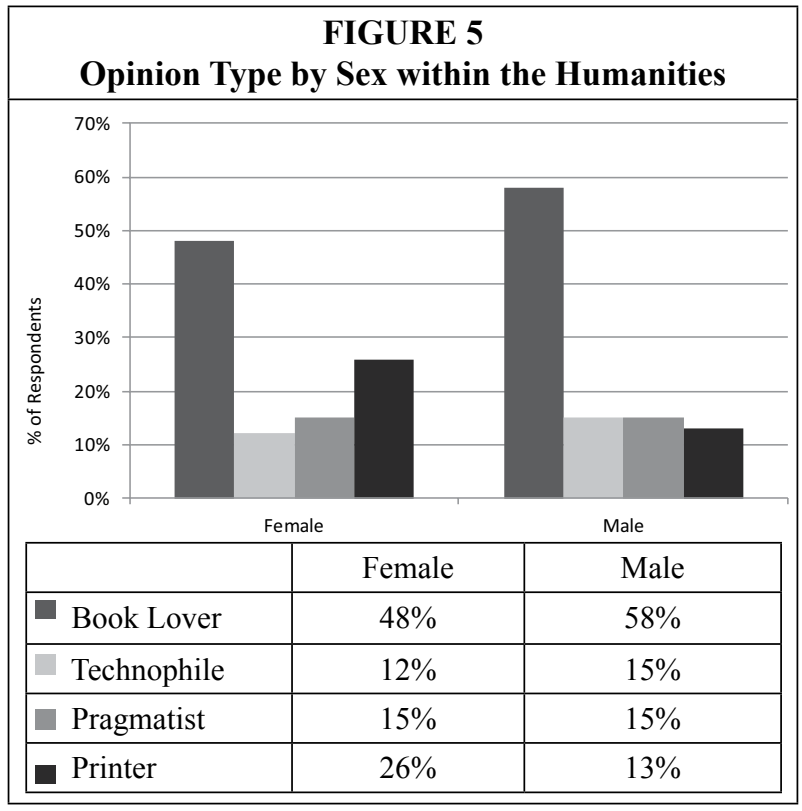

of independence confirmed that the differences between the three status distributions are statistically significant ( $p$ $=0.001)$. This indicates that undergraduates and graduates may be somewhat less devoted to the concept of the printed book than faculty, but are still likely to want information printed out for reading. All three status levels were similar in that approximately 60 percent of each group identified as either a Book Lover or Printer, the two most "print-friendly" opinions in our analysis. group, despite the predominance of men $(77 \%)$ in the sample.

Next, we examined differences between the academic statuses of respondents, where we see distinct patterns as well. A little over half $(55 \%)$ of our respondents were undergraduates, 18 percent were graduate students, and the remaining 27 percent were faculty and staff. Undergraduates and graduate students shared quite similar distribution patterns, with Book Lovers and Printers accounting for approximately 60 percent of respondents in each group (see figure 6). Undergraduates had a greater percentage of Technophiles, compared to Pragmatists ( $24 \%$ vs. $16 \%$ ), while graduate students were split evenly between the two (20\% Technophiles, $18 \%$ Pragmatists). This could indicate the increased level of research done by most graduate students and their willingness to use materials in whatever format is available. It also reiterates Wendy Shelburne's finding that graduate students tended to be the most open to both online and print materials. ${ }^{12}$ Faculty and staff were predominantly Book Lovers (43\%), with an even distribution among the remaining three opinion types. A chi-square test

\section{Conclusions and Implications}

Both the qualitative and quantitative data reflect the changing nature of book use. While only 23 percent of the participants at the time of the study fit into the Technophile opinion type, 17 percent were classified as Pragmatists and 26 percent were in the Printers group. Each of these groups, which altogether comprise 66 percent of the campus population, has some level of comfort with or acceptance of electronic books. As this survey was undertaken in spring 2009 when many patrons were still unfamiliar with specific e-reader devices such as the Kindle, Nook, iPad (to name but a few), many of those who had originally expressed concern about reading lengthy passages of text on a screen might now have those concerns alleviated. Book Lovers did still remain the largest plurality (34\%) of users, however. Many of the open-ended responses reiterated a preference for print by stating that they felt the library should purchase both print and e-books. Thus, while patrons may support the idea of e-books, there is hesitance to make a complete commitment to the format and many still indicated they would also like the option 
of print as well. With the extremely rapid changes in technology and an increasing number of e-books and platforms coming online and purchased in our system and broadly in society, we anticipate that a repeat of the survey would reveal changes in attitudes over time.

These findings have particular implications for collection development. While subject specialists may have intuitive feelings concerning their patrons' preferences of e-book versus print formats, this research provides quantitative data that may support or disprove those feelings or biases. Libraries may wish to engage in pilot projects or forays into e-books on a differential subject-specific level with these results in mind. With current interest in Patron-Driven Acquisition (PDA) models, librarians can receive immediate feedback of patron interest in specific titles. While these models are typically only available for e-books, they do provide a way to allow patrons to select only those titles they would like in electronic format, potentially saving both space and, most important, funds in these times of ever-increasing budget constraints. We are interested to see whether purchases of books in PDA programs follow a distribution of academic subjects that might be predicted from our data. Other possibilities include the addition of a print-on-demand system such as the Espresso Book Machines now in use at University of Michigan and University of Utah. While libraries may not be able to purchase materials in both online and print formats due to budget constraints, this technology could accommodate those who wish to have print copies of online materials. Electronic journal articles are often printed out as hard copies, and the same may become true for longer-format online materials. Just as we now accommodate different learning styles in the classroom, we can also accommodate the different e-book opinion types as well.

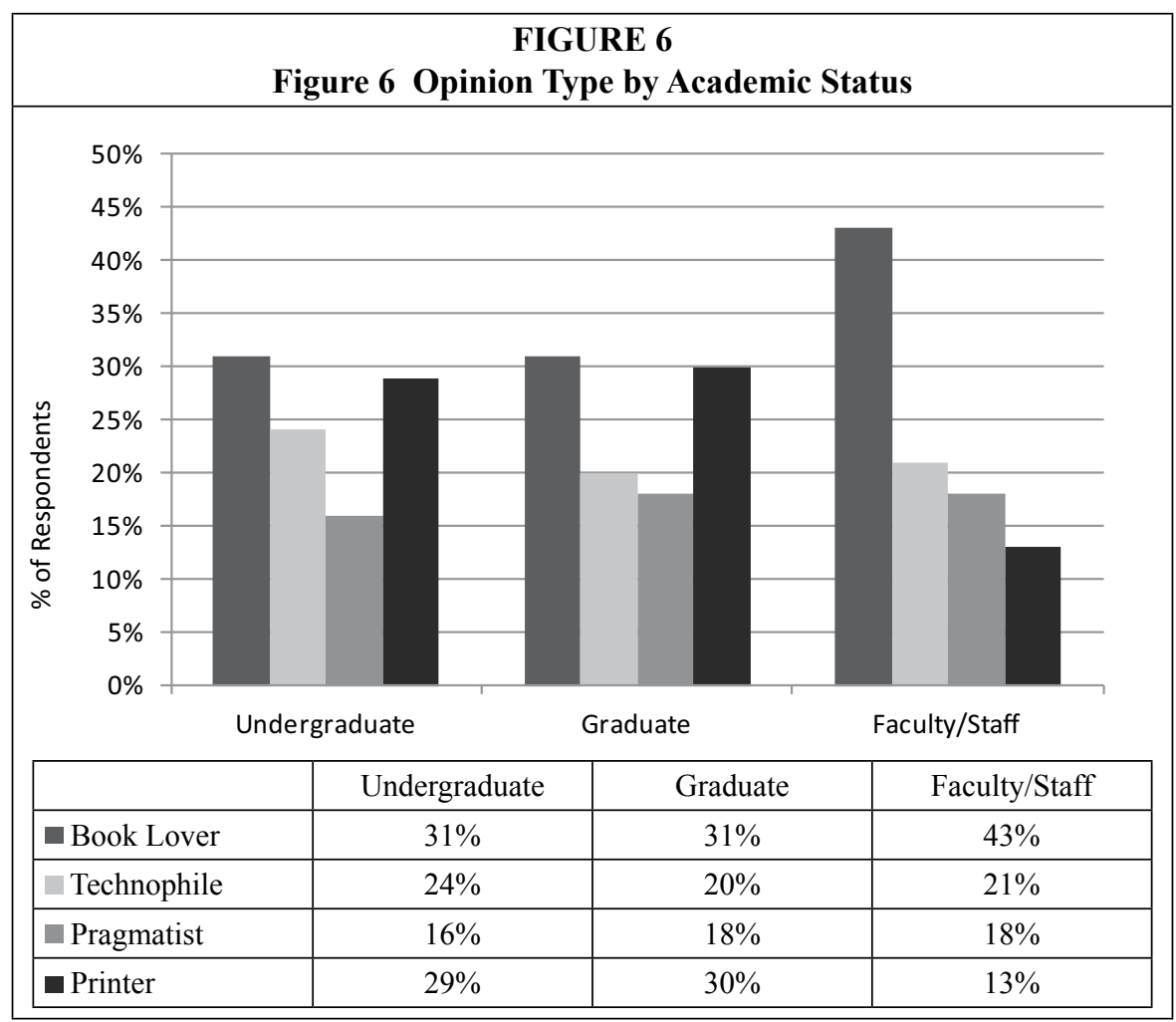




\section{Notes}

1. Aaron Shrimplin, Andy Revelle, Susan Hurst, and Kevin Messner, "Contradictions and Consensus: Clusters of Opinions on e-Books," College \& Research Libraries 72, no. 2 (2011): 181-90.

2. Steven R. Brown, "A Primer on Q Methodology," Operant Subjectivity 16, no. 3 (1993): 91-138; Steven R. Brown, "The History and Principles of Q Methodology in Psychology and the Social Sciences," available online at http://facstaff.uww.edu/cottlec/Qarchive/Bps.htm [accessed 18 August 2011]; Bruce McKeown and Dan Thomas, Q Methodology (Newbury Park, Calif.: Sage Publications, Inc., 1998).

3. Shrimplin, Revelle, Hurst, and Messner, “Contradictions and Consensus," 185-86.

4. "Electronic Book and e-Reader Device Report," On-Campus Research, available online at www.nacs.org/research/industrystatistics/oncampusresearchbriefs.aspx [accessed 3 January 2011].

5. Ian Rowlands, David Nicholas, Hamid R. Jalami, and Paul Huntington, "What Do Faculty and Students Really Think About e-Books?" Aslib Proceedings 59, no. 6 (2007): 489-511; Hamid R. Jamali, David Nicholas, and Ian Rowlands, "Scholarly e-Books: The Views of 16,000 Academics," Aslib Proceedings: New Information Perspectives 61, no. 1 (2009): 33-47; Caren Milloy, “Dispelling Myths about e-Books with Empirical Evidence," JISC Collections, available online at www.jiscebooksproject.org/wp-content/jc_ebooks_observatory_summary-final.pdf [accessed 13 May 2010]; David Nicholas, Ian Rowlands, and Hamid R. Jamali, "E-Textbook Use, Information Seeking Behavior and Its Impact: Case Study Business and Management," Journal of Information Science 36, no. 2 (2010): 263-80.

6. Primary Research Group, The Survey of American College Students: Student Use of Library E-book Collections (New York: Primary Research Group, 2009).

7. Global Faculty E-Book Survey, Ebrary, available online at www.ebrary.com/corp/newspdf/ ebrary_faculty_survey.pdf [accessed 13 May 2010]; 2008 Global Student E-Book Survey, Ebrary, available online at www.ebrary.com/corp/collateral/en/Survey/ebrary_student_survey_2008.pdf [accessed 13 May 2010].

8. Wendy Allen Shelburne, "E-Book Usage in an Academic Library: User Attitudes and Behaviors," Library Collections, Acquisitions, and Technical Services 33 (2009): 59-72; Danielle M. Carlock and Anali Maughan Perry, "Exploring Faculty Experiences with e-Books: A Focus Group," Library Hi Tech 26, no. 2 (2008): 244-54; Cynthia L. Gregory, "But I Want a Real Book': An Investigation of Undergraduates' Usage and Attitudes toward Electronic Books," Reference and User Services Quarterly 47, no. 3 (2008): 266-73; A. Noorhidawati and Forbes Gibb, "How Students Use e-Books: Reading or Referring?" Malaysian Journal of Library and Information Science 13, no. 2 (2008): 1-14; Peter Hernon, Rosita Hopper, Michael R. Leach, Laura L. Saunders, and Jane Zhang, "E-Book Use by Students: Undergraduates in Economics, Literature, and Nursing," Journal of Academic Librarianship 33, no. 1 (2007): 3-13; Lynn S. Connaway, Chandra Prabha, and Timothy J. Dickey, "The Whys and Hows of College and University User Satisficing of Information Needs, Phase III: Focus Group Interview Study," Ohio State University, available online at http://imlsproject. comm.ohio-state.edu/imls_reports/imls_PH_III_report_list.html [accessed 13 May 2010]; Michael Levine-Clark, "Electronic Book Usage: A Survey at the University of Denver," portal: Libraries and the Academy 6, no. 3 (2006): 285-99; K.T. Anuradha and H.S. Usha, "Use of e-Books in an Academic and Research Environment: A Case Study from the Indian Institute of Science," Program: Electronic Library and Information Systems 40, no. 1 (2006): 48-62.

9. A.K. Shrimplin and A.A. Revelle, "Conflict and Consensus: Clusters of Opinion on e-Books" (paper presented at the biannual conference of the Association of College and Research Libraries, Mar. 13, 2009).

10. Hamid, Nicholas, and Rowlands, "Scholarly e-Books," 41; Rowlands, Nicholas, Hamid, and Huntington, "What Do Faculty and Students Really Think About e-Books?" 10; Shelburne, "E-Book Usage in an Academic Library," 65.

11. Rowlands, Nicholas, Hamid, and Huntington, "What Do Faculty and Students Really Think About e-Books?" 10.

12. Shelburne, "E-Book Usage in an Academic Library," 65. 


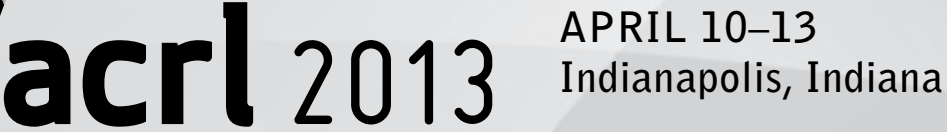 peer revered}

\section{ACRL 2013: Imagine, Innovate, Inspire}

In today's fast-paced and changing world, keeping current is more essential than ever. The ACRL 2013 Conference features more than 300 carefully curated programs to help you stay at the forefront of the profession. Access cutting-edge information, discover new ideas, and engage in conversations with academic and research librarians from around the world at ACRL 2013.

\section{Register now and save!}

Registration and housing materials are now available. Register by the earlybird deadline to take advantage of discounted fees. Save $\$ 70$ or more! Group discounts up to $20 \%$ and scholarships are also available. Materials are online at www.acrl.org/acrlconference.

\section{Submit a proposal}

Share your imagine, innovation, and inspiration with your colleagues. Cyber zed shed, poster session, roundtable discussion, and virtual conference webcast proposals are due November 9, 2012. Check out the Call for Participation online for complete details.

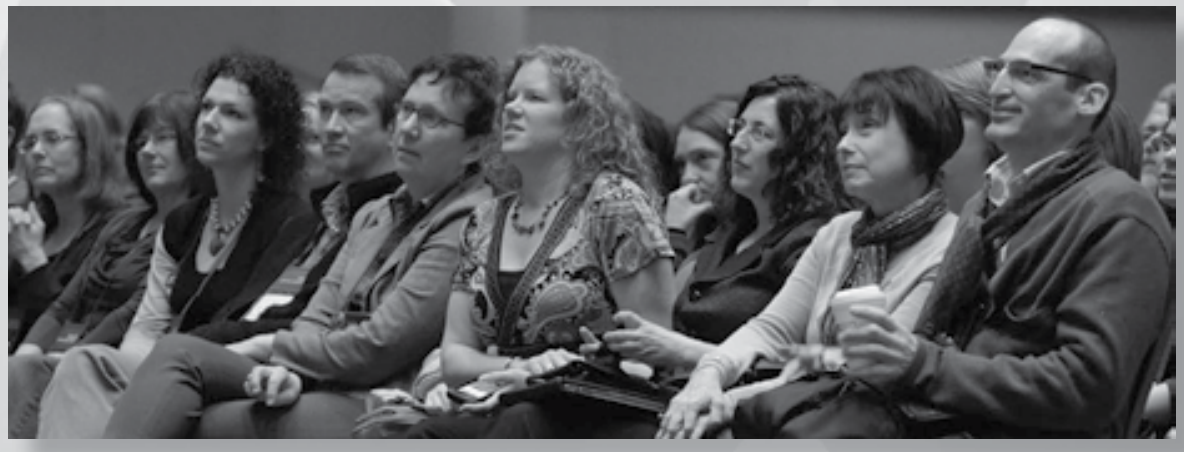

